\title{
Effect of Acidity on Delta 7 Stigmastenol Content of Palestinian Olive Oil
}

\author{
${ }^{1}$ Jihad M. Quasem, ${ }^{2}$ Ibrahim Abdullah Afaneh, ${ }^{3}$ Harbi T. Al-Masri, \\ ${ }^{4}$ Muhammad A. Hmidat, ${ }^{5}$ Ayman Suliman Mazahreh and ${ }^{6}$ Ahmad Sandookah
}

\author{
${ }^{1}$ Deanship of Educational Services College, \\ Taibah University, Al-Madina Almnura, Saudi Arabia \\ ${ }^{2}$ Department of Food Processing, Faculty of science and Technology, \\ Al-Quds University, P.O. Box 20002, Jerusalem \\ ${ }^{3}$ Department of Applied Chemistry, \\ Faculty of Applied Sciences, Taibah University, Al-Madina Amnura, Saudi Arabia \\ ${ }^{4}$ Al-Reef for Investment and Agricultural Marketing- PARC \\ Building, Al-Ma'aahid Street, Ramallah P.O. Box 25128, Shufat \\ ${ }^{5}$ Department of Applied Sciences, Princes Alia University College \\ Al-Balqa Applied University, Amman 11194, Jordan \\ ${ }^{6}$ Department of Food Science and Nutrition, \\ Faculty of Allied Medical Sciences, Applied Science University, Amman, Jordan
}

Received 2012-06-06, Revised 2012-10-06; Accepted 2012-11-07

\begin{abstract}
Olive oil quality is a term influenced by many factors. $\Delta 7$ Stigmastenol is a new criteria used to determine olive oil quality especially its purity from adulteration with other types of seeds oil. $\Delta 7$ Stigmastenol-acidity correlation were investigated through studying the effect of the literature's highlighted factors, namely; Olive fly infection, the land topographic and the preservation of olive before pressing. In this study, 13 olive samples were collected and analyzed from different areas in Palestine to study the factors that affect $\Delta 7$ Stigmastenol in Olive Oil. This study starts on October 2007 and ends on July 2008. The results obtained were very interesting and varied between having positive $\Delta 7$ Stigmastenol-acidity correlation as in case of infection mode factors and preservation of olive fruit before pressing negative $\Delta 7$ Stigmastenol-acidity correlation for other factors as found to the land topographic factors. Further studies are needed to investigate the correlation between acidity and other factors.
\end{abstract}

Keywords: $\Delta 7$ Stigmastenol, Acidity Correlation, Olive Oil Quality, Highlighted Factors, Determine Olive, Between Having, Before Pressing, Quality Especially

\section{INTRODUCTION}

Olive oil is one of the oldest culinary oils, basically extracted from the olive fruit that is originated from the Mediterranean region. In ancient Athens, the olive was a symbol of the city's prosperity and its oil was used both in cooking and as fuel for oil-burning lamps (Stradley, 2004).
There are four chemical olive oil major parameters used to study these correlations, namely; acidity percentage and peroxide value, where these two chemical criteria are quality parameters and are well known for grading the olive oil in terms of quality. The other two chemical parameters are iodine value and saponification number which are olive oil purity parameters like $\Delta 7$ Stigmastenol that is intended to detect the adulteration of olive oil with other seed oils.

Corresponding Author: Jihad M. Quasem, Deanship of Educational Services College, Taibah University, Al-Madina Almnura, Saudi Arabia 
In the years 2004 and 2005, most of the Palestinian olive oil contained $\Delta 7$ Stigmastenol more than $0.7 \%$ which is higher than the international standards $(\leq 0.5 \%)$ (IOOC, 2009). Unfortunately this problem is a threat to lose the Palestinian olive oil outside market. In fact, some containers of the Palestinian olive oil were rejected from European ports due to $\Delta 7$ Stigmastenol high results.

This problem of the higher $\Delta 7$ Stigmastenol in the Palestinian olive oil leads to investigate the factors that could be affecting $\Delta 7$ Stigmastenol and how these factors could be controlled to solve this problem (PCBS, 2009).

To solve this huge problem, the Palestinian olive oil needed to be studied for determining the natural content of $\Delta 7$ Stigmastenol. This investigation were pointed some assumptions about these highlighted factors. The following three factors were chosen to study their effect on $\Delta 7$ Stigmastenol: olive fly infestation, topographic land and olive fruit storage before pressing

$\Delta 7$ Stigmastenol is one sterol from 15 sterols found in olive oil. Sterols, which comprise a major portion of the unsaponifiable matter, are found in almost all fats and oils and they are also an indicator of the genuine vegetable oils. Sterol and alcohol profiles are used to characterize virgin olive oils and especially to detect the adulteration of olive oil with hazelnut oil.

The importance of this study is to investigate the effect of the acidity on $\Delta 7$ Stigmastenol, thus manifesting the "acidity- $\Delta 7$ Stigmastenol correlation", for olive oil without adultera

\section{MATERIALS AND METHODS}

\subsection{Olive and Olive Oil Sampling}

Studying the five factors needs to make one factor variable while the other factors were stable as could. As a result, the 13 samples were collected as olive of $5 \mathrm{~kg}$ for each sample to produce around one liter of olive oil and press by semi-manual small press.

\subsection{The Effect of Olive Fly}

Two olive samples were collected from Jenin area, each $5 \mathrm{~kg}$, one was infected with olive fly and the other was not infected.

\subsection{The Topographic}

Two olive samples were collected in a size of $5 \mathrm{~kg}$ for each from two different topographical areas in Jenin (level land and mountainous land).

\subsection{Olive Storage Before Pressing}

10 olive samples were collected from Hebron area, each sample $5 \mathrm{~kg}$. 5 samples of them were stored in plastic bags, where the other 5 samples were stored in net plastic boxes for 27 days with intervals of 1 week (7 days). Each storage time, one sample from both: plastic bag and net plastic box were pressed for extracting oil.

The total period for this test started in December 2007 to July 2008.

\subsection{Methodology of Oil Extraction}

The other 15 olive samples were pressed by small press designed by the researcher and it consists of screw crusher driven by electrical motor to crush the olive fruit. Small semi-manual mixer was used to mix the olive paste with warm water (malaxation). Manual hydraulic presser which produces 4 tons of pressure was used to separate the liquid phase from the pomace. And small centrifuge device was used to separate olive oil from liquid phase which provides a rotation of $6000 \mathrm{rpm}$.

\subsection{Analytical Test}

There was one analytical test done, which was sterol composition and distribution, where the $\Delta 7$ Stigmastenol is present. This test was done by using CapillaryColumn Gas Chromatography according to the IOOC. The run took place in the Royal Scientific Society in Jordan, as it was not available in Palestine. While the acidity tests were carried out according to IOOC standards (IOOC, 2001).

\section{RESULTS AND DISCUSSION}

Since the major olive oil chemical test is oil acidity, the eleven factors mentioned in the literature were found to have a great influence on acidity value. This study is an attempt to establish a correlation between olive oil acidity and $\Delta 7$ Stigmastenol under the eleven factors highlighted in this investigation. Each factor will be discussed separately.

\section{1. $\delta 7$ Stigmastenol-Acidity Correlation Under the Infection Mode Factor}

Olive oil samples derived from infected fruit and non infected fruit were analyzed for their acidity, as shown in Fig. 1.

However, its effect was much higher on acidity than on $\Delta 7$ Stigmastenol. The acidity percentage increased more than four times in case of infection, while the $\Delta 7$ Stigmastenol value was almost duplicated due to the infection. This is due to the action of fly in freeing lipase enzyme which was higher in producing free fatty acids than affecting the sterols. 
Same finding was illustrated by Pereira et al. (2004), who stated that "olive oils, in general, obtained from infected olives had higher acidity values. The holes made by the olive fruit fly allow bacteria and fungi to entrance and develop of which increases the damage and breakdown in the olive pulp".

Another finding was illustrated by Tamendjari et al. (2004), who found that the values of acidity and peroxide increased in oils obtained from fly-infested olives. These results are due to the hydrolytic and oxidative processes which were favored by the exit holes, by exposing the olive pulp to environmental influences.

Less pronounced finding was reported by Salvador et al. (2000), who stated that the increase of free acidity is mainly due to enzyme activity caused by olive oil tissue damage.

\section{2. $\Delta 7$ Stigmastenol-Acidity Correlation Under Topographic Land Factor}

An opposite correlation between acidity and $\Delta 7$ Stigmastenol was found due to the role of Topographic Land, as illustrated by Fig. 2. Although the differences between the $\Delta 7$ Stigmastenol results in relation to topographic land was very small, it was clear that $\Delta 7$ Stigmastenol was smaller in the level land than in the mountainous land.

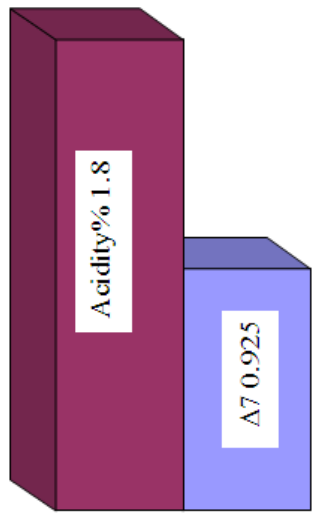

Infected

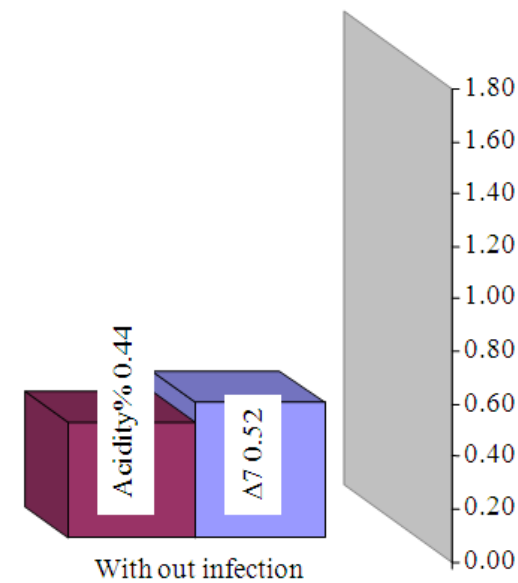

Fig. 1. Relation between $\Delta 7$ stigmastenol and acidity percentage under the infection mode factor

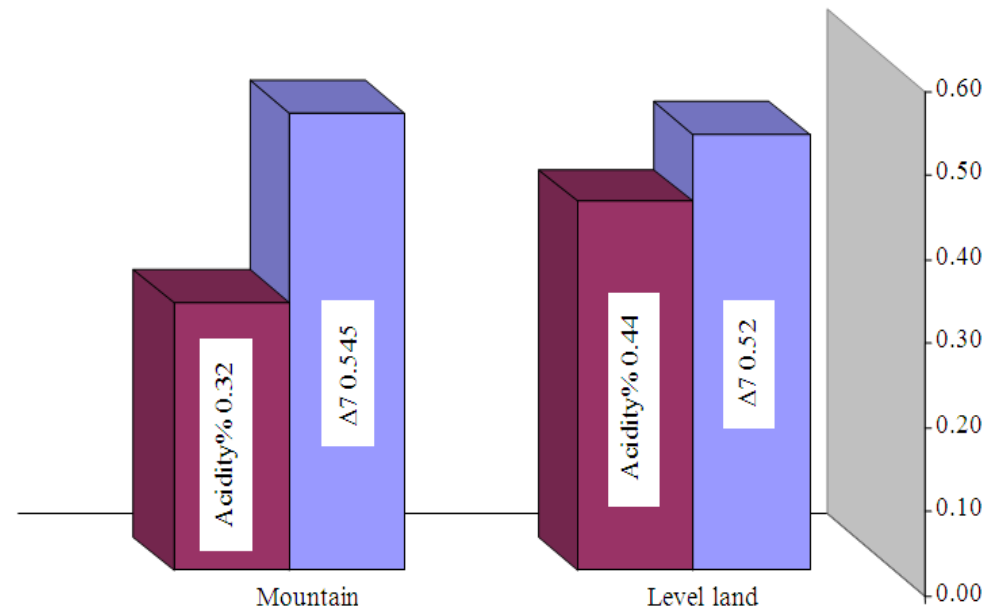

Fig. 2. Relation between $\Delta 7$ stigmastenol and acidity percentage under the topographic land factor 
Contradicting results were found for acidity. The higher value was related to the level land and the differences in the acidity results were more visible. This finding is probably caused by the differences in the climate between the two different lands as well as the water content.

\section{3. $\Delta 7$ Stigmastenol-Acidity Correlation Under Olive Fruit Storage Factor}

One of the olive fruit handling which is storage container prior to pressing is studied. $\Delta 7$ Stigmastenol and acidity results of the two different containers, the plastic bags and the plastic boxes, are shown in Fig. 3b and d, respectively.

Figure 3a shows that the acidity of olive oil increases exponentially with the increasing storage time of the fruit in plastic bags while the acidity percentage of olive oil increased in linear mode with increasing the $\Delta 7$ Stigmastenol, as shown Fig. 3b.

At the same time olive oil acidity increased exponentially with increasing the storage time of the fruit stored in plastic box (Fig. 3c). The same correlation was found for samples derived from olive fruit stored in plastic box, as shown in Fig. 3d.

However, the increase in fruit stored in plastic bags was sharper than the increase for those which were stored in plastic boxes.

During fruit storage, the lipase enzyme activates with time, meaning that the acidity percentage increases. Also there are some fermentation processes that occur during fruit storage with time, which affect the sterolic content in olive oil.

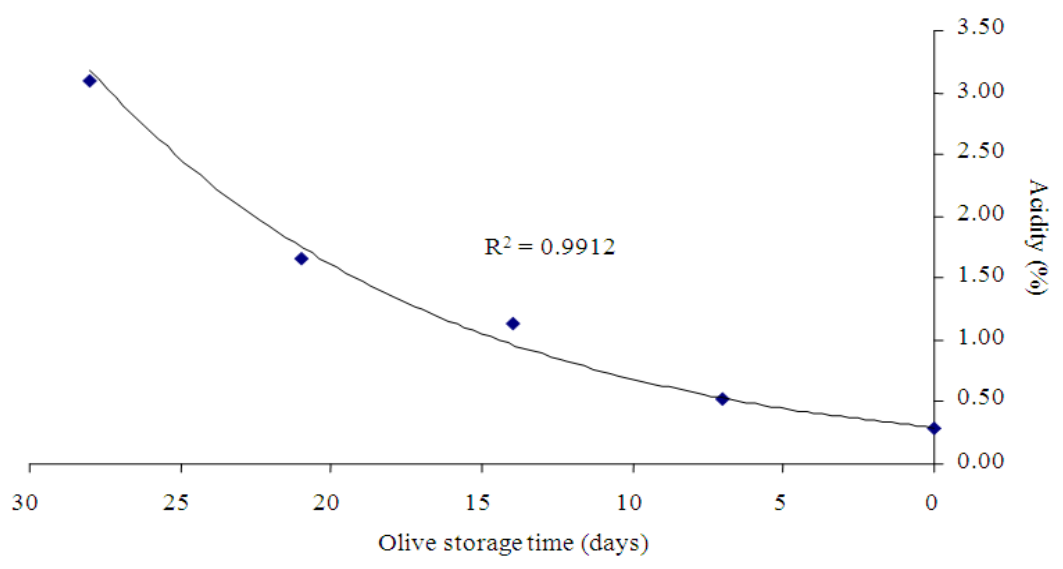

Fig. 3a. Relation between acidity percentage and olive storage time before pressing and in plastic bags

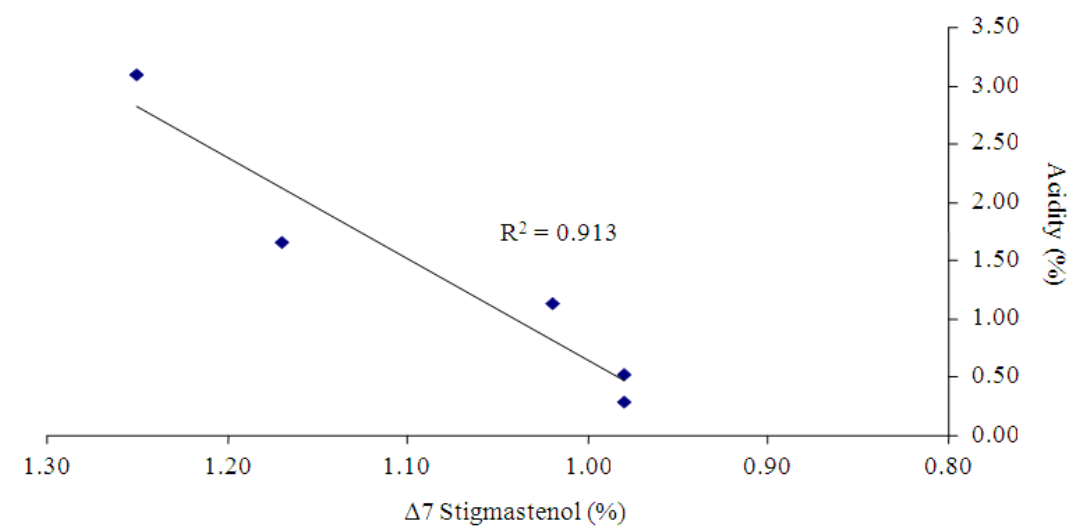

Fig. 3b. Relation between $\Delta 7$ stigmastenol and acidity percentage under the olive storage factor in plastic bags 


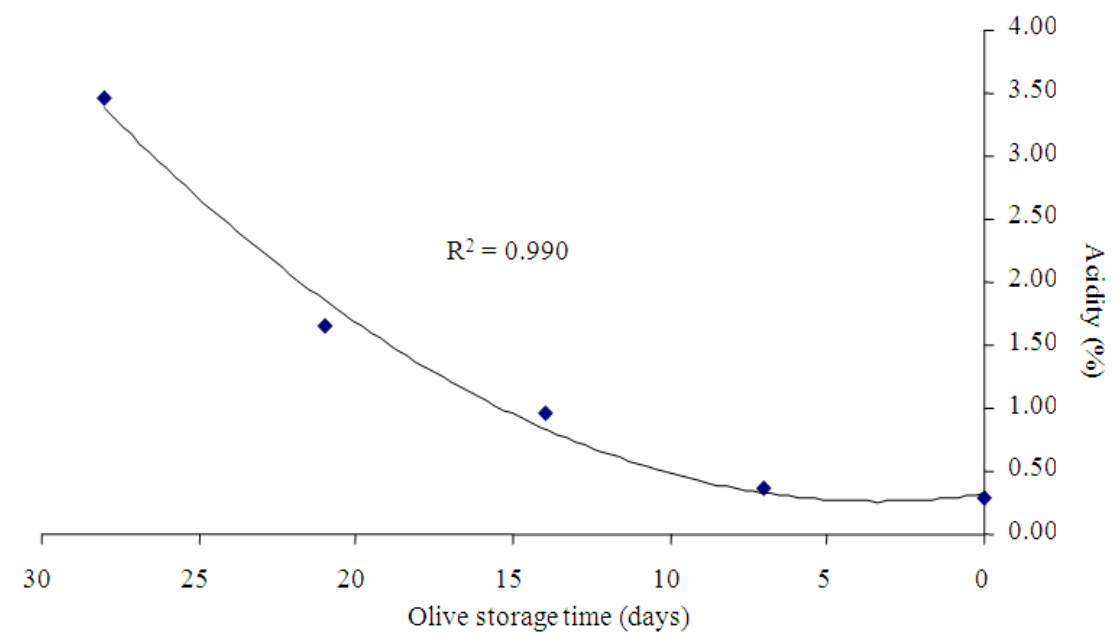

Fig. 3c. Relation between acidity percentage and olive storage time before pressing in plastic boxes

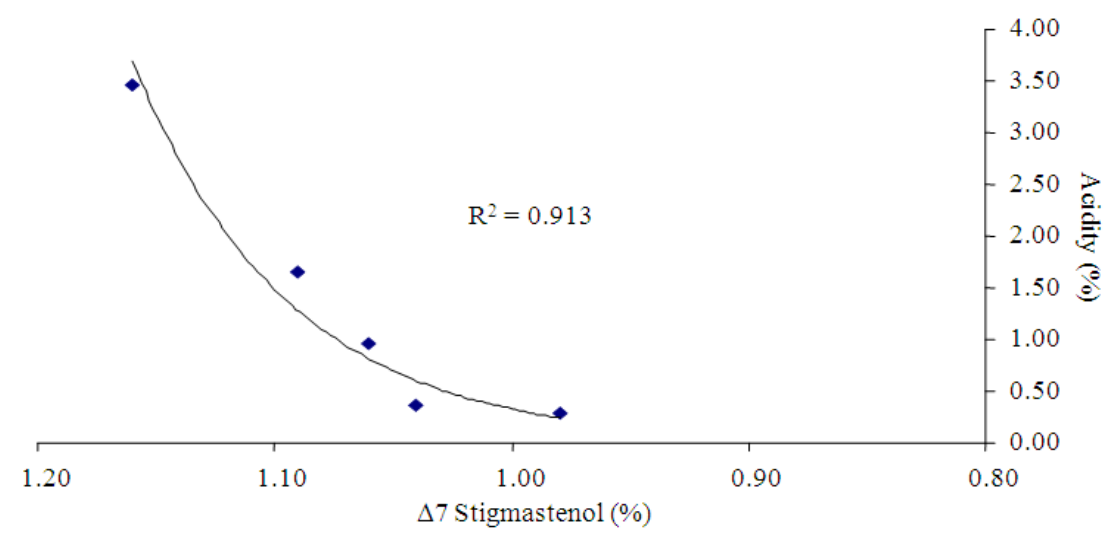

Fig. 3d. Relation between $\Delta 7$ stigmastenol and acidity percentage under the olive storage factor in plastic boxes

Koprivnjak et al. (2002), found that Acidity, the consequence of hydrolytic enzymes activity in destroyed cells, increased markedly after 10 days in fruits from reticular bags, while in plastic bags this was evident only after 15 days of storage.

\section{CUNCLUSION}

The results for the correlations between $\Delta 7$ Stigmastenol and acidity indicated that under the infection mode factor, D7 Stigmastenol showed a positive relationship with acidity percentage, where as olive infection increases, both $\Delta 7$ Stigmastenol and acidity percentage increase.
$\Delta 7$ Stigmastenol has a negative relationship with acidity percentage for land topographic factor.

For the factor of olive fruit storage before pressing, $\Delta 7$ Stigmastenol has a positive relationship with acidity, where the effect in plastic bags is sharper than in plastic boxes. However, $\Delta 7$ Stigmastenol has a negative relationship with iodine value and sensory mark, where the effect in plastic bags is sharper than in plastic boxes.

\section{ACKNOWLEDMENT}

Special thanks goes the Palestinian Agricultural Relief Committee (PARC) and ACDIVOCA-USAID for the financial support of this study. 


\section{REFERENCES}

IOOC, 2001. Method of analysis: Determination of the composition and content of sterols by capillarycolumn gas chromatography. International Olive Oil Council.

IOOC, 2009. Trade standard applying to olive oil and olive-pomace oil. International Olive Oil Council.

Koprivnjak, O., L. Conte and N. Totis, 2002. Influence of olive fruit storage in bags on oil quality and composition of volatile compounds. Food Technol. Biotechnol., 40: 129-134.

PCBS, 2009. Palestinian figures. Palestinian Central Bureau of Statistics.
Pereira, J.A., M.R. Alves, S. Casal and M.B.P.P. Oliveira, 2004. Effect of olive fruit fly infestation on the quality of olive oil from cultivars cobrancosa, madural and verdeal transmontana. Ital. J. Food Sci., 16: 355-365.

Salvador, M.D., F. Aranda, S. Gomez-Alonso and G. Fregapane, 2000. Quality characteristics of Cornicabra virgin olive oil. Res. Adv. Oil Chem., 1: 1-9.

Stradley, L., 2004. Linda's culinary and food dictionary and glossary-A to Z. What's Cooking America.

Tamendjari, A., F. Angerosa and M.M. Bellal, 2004. Influence of Bactrocera oleae infestation on olive oil quality during ripening of Chemlal olives. Ital. J. Food Sci., 16: 343-354. 